\title{
A BETA-COUNTING SYSTEM LINKED TO A PERSONAL COMPUTER
}

\section{KUNIO OMOTO}

Radiocarbon Dating Laboratory, Department of Geography, College of Humanities and Sciences Nihon University, 25-40, 3-Chome, Sakurajosui, Setagaya-Ku, Tokyo 156 Japan

\begin{abstract}
The automatic $\beta$-counting system plays a significant role in obtaining high-level reproducibility and reliability in conventional radiocarbon dating. I review here the results achieved by using the "Fully Automatic Radiocarbon Dating System" developed by Omoto (1982). Since setting up the system in 1981, I was able not only to save operator time in $\beta$ counting, but also to obtain accurate dates with only minimal uncertainties. Another positive result was the introduction of the automatic voltage correction program, which produced excellent results for counting sample materials over a long period.
\end{abstract}

\section{INTRODUCTION}

Since the development of the radiocarbon dating method by W. F. Libby and co-workers (Arnold and Libby 1949; Libby, Anderson and Arnold 1949; Anderson, Arnold and Libby 1951; Arnold 1954; Libby 1955), scientists have continually improved the technology. The remarkable progress of the 1980s was furthered by the advent of accelerator mass spectrometry (AMS) and liquid scintillation counting (LSC). In many ${ }^{14} \mathrm{C}$ dating laboratories throughout the world, measurements are made using the gas-proportional counting system. Hence, few laboratories are likely to carry out a $\beta$-counting experiment controlled by a desktop computer and an interface connected with instruments.

Soini and Kojola (1977) constructed a microprocessor-controlled instrument for counting tritium. This seems to have been the first reported application of a microprocessor in a gas counter. Schoch et al. (1980) discussed an electronic data-acquisition system connected to a DEC PDP-11/03 microcomputer. Although operational details were given, these systems did not control the instruments (i.e., their operating voltage).

Omoto (1982) developed a BASIC program linked to a personal computer (NEC PC-8001), as well as a fully automatic ${ }^{14} \mathrm{C}$ dating system. I described an algorithm and discussed the hardware and software, thus providing a new opportunity for continuous counting in gas-proportional counting by using an automatic sample changer. Otlet et al. (1983) described a NASCOM microprocessor for data collection. Walanus (1986) advocated quality control by microcomputer. Hertelendi et al. (1989) described their analog and digital data processing system with software written in BASIC, using assembler subroutines. Van der Plicht, Streuman and Schreuder (1992) introduced a new data acquisition system for the Groningen counters. They used an XT-compatible PC and connected the GPIB/IEEE-488 bus to 11 counters.

With the exception of Omoto (1982) and van der Plicht, Streuman and Schreuder (1992), the reports provide neither algorithms nor precise descriptions of hardware and software programs. I present here some guidelines and expertise for scientists and technicians interested in controlling their $\beta$ counting instruments with a desktop computer connected to an interface.

\section{METHODS}

\section{Hardware}

The basic components of the automatic $\beta$-counting system are a personal computer, an interface and several measuring instruments. In 1981, I purchased a NEC PC-8001 computer system; I later exchanged it for a PC-8801, followed by models for the PC-9801 series, as the newer models pro- 
vided a high-speed CPU, large memory and built-in hard disk. In recent years, I have used several notebook-style PCs to save space in the laboratory. I am now able to use any kind of PC with an RS$232 \mathrm{C}$ communication interface.

The interface is connected to a timer, three-channel scalers (connected to two-channel amplifiers for center and guard counter), two digital voltmeters, a digital manometer and a digital thermometer connected to a gas-proportional counter (Fig. 1). Its first function is to control instruments, which means that it can regulate the tuning of high-voltage units for center and guard counters with $\pm 2 \mathrm{~V}$. In 1982, I used two pulse motors connected with two variable resistances to change high voltage. But soon I substituted faster A/D (analog/digital) and D/A (digital/analog) converter boards for high-voltage control. The interface can also control eight relays connected with electric circuits (e.g., power supply units, high-voltage units, vacuum line valves), and it can regulate a timer. Another function is to read data from the measuring instruments and transmit them to a host PC (CPU). The interface has a communication line (RS-232C) that sends and receives commands and data to and from the host computer. Details of the recent automatic ${ }^{14} \mathrm{C}$ dating system are shown in Table 1.

\section{Software}

Figure 2 is a flowchart of the automatic $\beta$-counting system. I originally wrote the program in BASIC, and later adapted it to operate under MS-DOS. Although many ${ }^{14} \mathrm{C}$ dating programs have been written since 1980 , I describe here only the main program for the $\beta$-counting experiment.

The program consists of several subroutine programs which include plateau counting, selection of operating voltage, $\beta$ counting, check of operating voltage, totalization (statistics), age calculation,

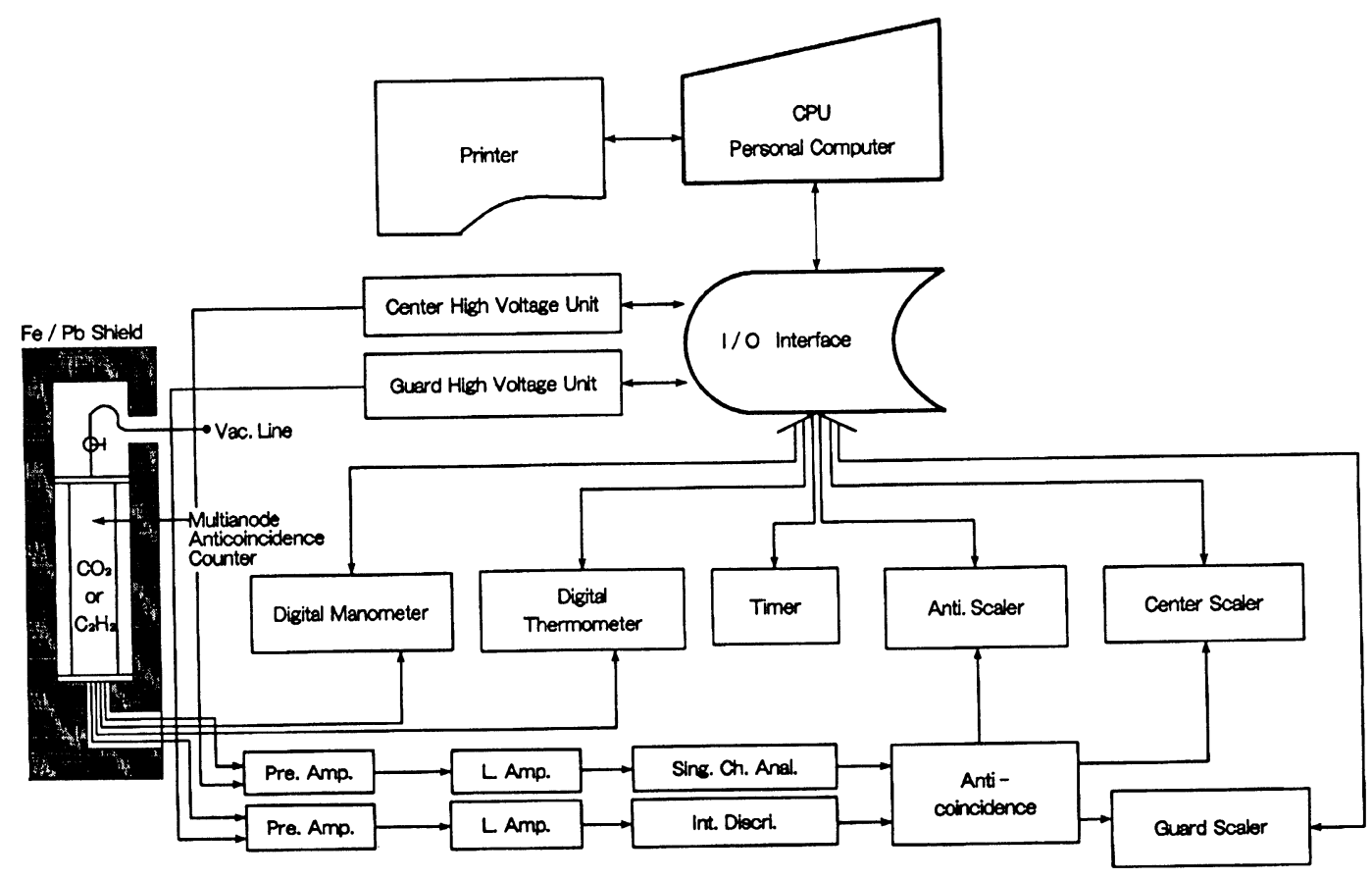

Fig. 1. Schematic diagram of an automatic ${ }^{14} \mathrm{C}$ dating system (after Omoto 1985) 
TABLE 1. Sample Specifications for a Recent Automatic ${ }^{14} \mathrm{C}$ Dating System

\begin{tabular}{|c|c|c|c|}
\hline Instrument & Model & Manufacturer & Accuracy or standard \\
\hline Computer & PC-9801 NS/R & NSC Co., Ltd. & $\begin{array}{l}\text { CPU i386 }{ }^{\mathrm{TM}} \mathrm{SL} \\
32 \mathrm{MHz}\end{array}$ \\
\hline Printer & PC-PR101/G3 & NEC Co., Ltd. & A4 page printer \\
\hline Interface & OJY-8201 & $\begin{array}{l}\text { Yoshiki Kogyo } \\
\text { Co., Ltd. }\end{array}$ & $\begin{array}{l}\text { Input } 5 \mathrm{ch} \\
\text { Output } 2 \mathrm{ch} \\
\text { Relay } 8 \mathrm{ch} \\
\text { I/O RS-232C }\end{array}$ \\
\hline $\begin{array}{l}\text { Multi-anode } \\
\text { anticoincidence } \\
\text { counter }\end{array}$ & S-1859 & $\begin{array}{l}\text { Ohyo Koken } \\
\text { Kogyo Co., Ltd. }\end{array}$ & $\begin{array}{l}\text { Volume } 1.2 \text { liter } \\
\mathrm{BKG}<3 \mathrm{cpm}\end{array}$ \\
\hline Amplifiers & See Fig. 1 & $\begin{array}{l}\text { Ohyo Koken } \\
\text { Kogyo Co., Ltd. }\end{array}$ & \\
\hline High voltage units & S-1064 & $\begin{array}{l}\text { Ohyo Koken } \\
\text { Kogyo Co., Ltd. }\end{array}$ & $\begin{array}{l}0-6000 \mathrm{v} \\
0.05 \%( \pm \mathrm{mm} \mathrm{Hg})\end{array}$ \\
\hline $\begin{array}{l}\text { Digital } \\
\text { manometer }\end{array}$ & $2655-14$ & $\begin{array}{l}\text { Yokogawa } \\
\text { Electric Co., Ltd. }\end{array}$ & $\begin{array}{l}0-1765 \mathrm{mmHg} \\
0.05 \%( \pm 0.01 \mathrm{~mm} \mathrm{Hg})\end{array}$ \\
\hline $\begin{array}{l}\text { Digital } \\
\text { thermometer }\end{array}$ & TR-2114 & $\begin{array}{l}\text { Advantest Co., } \\
\text { Ltd. }\end{array}$ & $\begin{array}{l}-200 \text { to }+649^{\circ} \mathrm{C} \\
0.06 \%\left( \pm 0.1^{\circ} \mathrm{C}\right)\end{array}$ \\
\hline
\end{tabular}

parameter input, data printout, relay control, tuning high voltage units, graphic displays, guard counter plateau measurement and temporary data printout.

In a ${ }^{14} \mathrm{C}$-dating experiment, the data essential for obtaining reliable dates and for verifying the experiments are time of counting, anticoincidence counts, center counts, guard counts, pressure and surface temperature of the counter and high-voltage figures for center and guard counters. The system can provide periodic automatic logging of instrumental parameters, which can be helpful during fault diagnosis.

\section{RESULTS AND DISCUSSION}

After the main program starts, the CPU initializes and reads the parameters and present figures of the instruments. The host PC asks the operator to input parameters from the keyboard: laboratory code number, name of the operator, time interval (measurement cycles) for data sampling, preset time of sampling and other information about the sample. Then the plateau measurement subroutine starts. The plateau condition needs to be checked before and after a long period of $\beta$ counting. After the plateau curve is drawn, a subroutine begins that determines operating high voltage. The purity high voltage and initial operating high voltage are determined as follows: After plateau measurement, a figure equal to half the count rate of the initial plateau is calculated. Then two precise count rates are measured at $50 \mathrm{~V}$ higher and lower than the initial purity high voltage. Based on those data, the CPU calculates purity high voltage and initial operating voltage. High-voltage adjustments for center and guard counters are based on the estimated figures. The $\beta$-counting subroutine then starts.

One can make online checks and adjustments of the operating high voltage for the gas-proportional counter at any programmed intervals throughout the $\beta$-counting experiment. I programmed them at $2 \mathrm{~h}$ after plateau measurement, and every $5 \mathrm{~h}$ thereafter. The results are shown in Figure 3 . Use of 

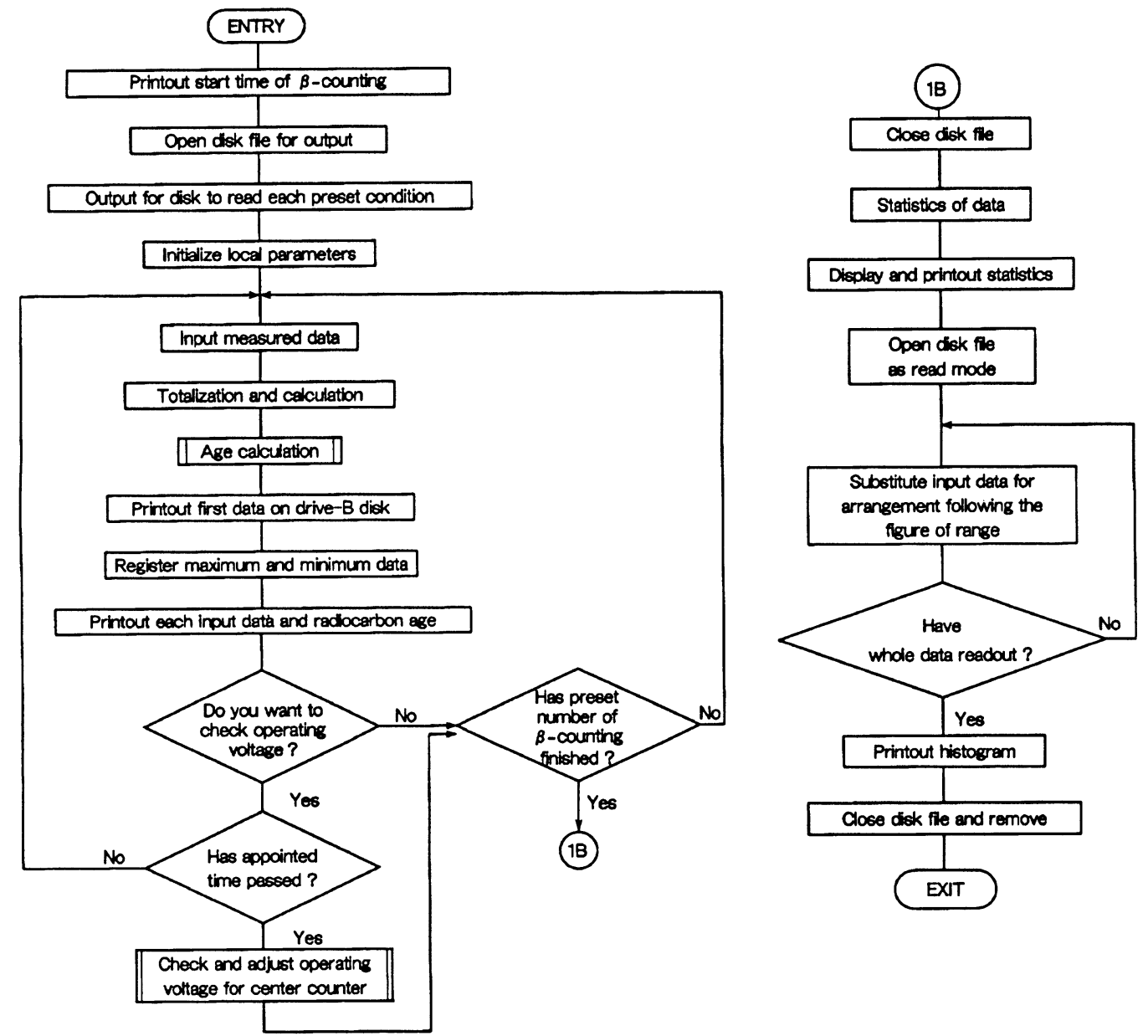

Fig. 2. Flowchart of $\beta$-counting program (after Omoto 1982)

this system also led to the discovery of shifts in optimum high voltage over a longer period of $\beta$ counting (Fig. 3D). That is, after the first $2 \mathrm{~h}$ of $\beta$ counting, the optimum high voltage shifted slightly from initial voltage to the negative side (Fig. 3E), although it shifted from the negative to the positive side in the following $5 \mathrm{~h}$ of $\beta$ counting (Fig. 3F). It is clear that the optimum high voltage shifted from initial voltage to the positive side gradually through $2000 \mathrm{~min}$ of $\beta$ counting (Fig. 3E$\mathrm{K})$. I postulate the following causes: 1 ) heterogenous gas diffusion taking place in the counter, i.e., the shift of operating high voltage may be caused by starting the $\beta$-counting experiment without allowing enough time after the sample gas has sublimed and filled the counter; 2) increase in impurifications in the counter over a long period of $\beta$ counting. It is possible to estimate them by monitoring the purity voltage and its counting rate. The automatic voltage correction program produced excellent results with long periods of $\beta$ counting.

While the program is running, all the data measured at every interval are displayed on the monitor screen and printed out. Using these figures, the CPU calculates and displays temporary age at each interval. All raw data are stored on a floppy disk or a hard disk (or on a $\mathrm{CD}$ ) to permit future offline 

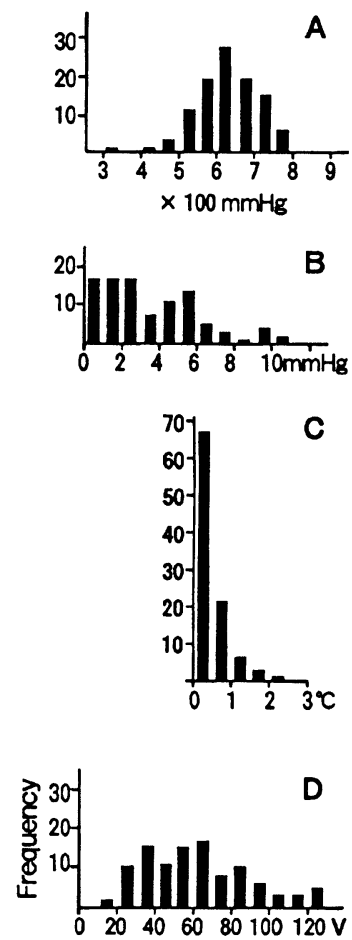
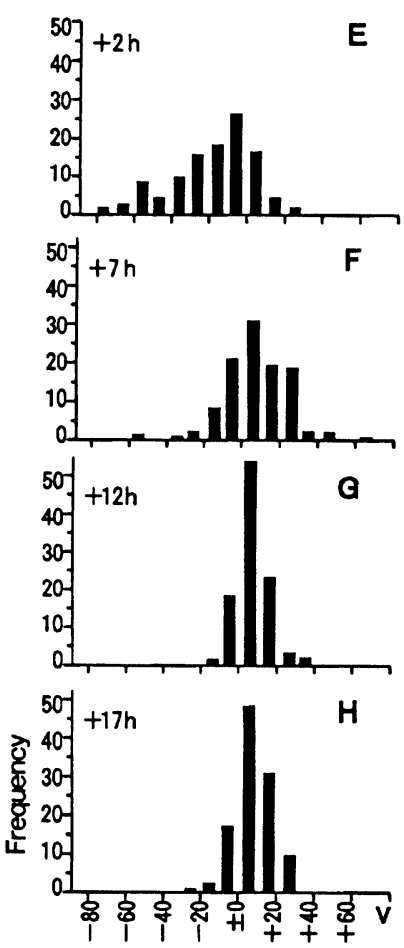
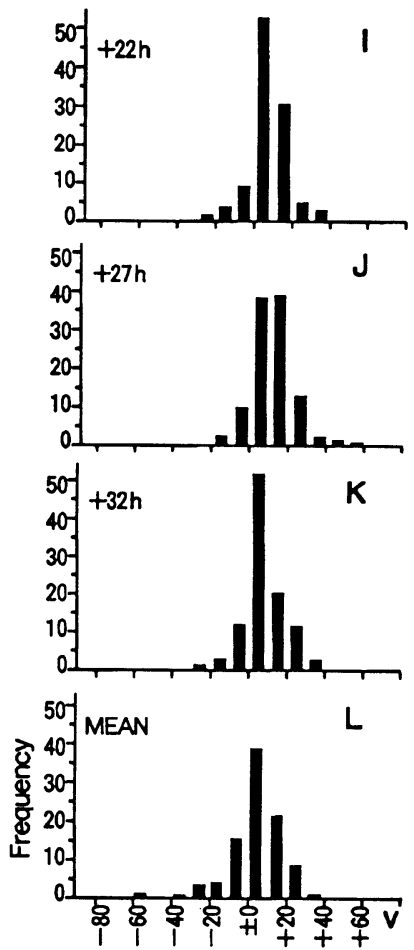

Fig. 3. Graphs indicating changes in counting conditions and optimum operating high voltage in $\beta$-counting experiments: A. counter filling pressure; B. pressure drift; C. temperature drift; D. maximum shifts of operating high voltage from start to finish; E-K. corrected optimum high voltage throughout a long period of $\beta$-counting experiments (elapsed time is shown in the upper left corner of each graph); L. total average of shifted optimum operating high voltage (E-K).

analysis, although a preliminary view of the data can be carried out online or printed out. One may also display and print out the data using another software program.

At the end of the count time, the file is closed and another subroutine program executes totalization, statistical analysis and age calculation. The results are shown on the monitor screen and printed out. Histograms of anti, center, and guard counts are also shown. After $\beta$ counting, the last subroutine checks the plateau and operating high voltages. The opening job-selection menu then appears on the monitor screen. The age may be calculated offline.

The new system was also able to eliminate cases of human error, for example, misreading instruments. I have found that the system can save as much as $99 \%$ of operator time, and produces accurate dates with a very small margin of uncertainty.

\section{ACKNOWLEDGMENTS}

I would like to dedicate this paper to the late Mr. Masatoshi Jinno, who helped me develop the automatic ${ }^{14} \mathrm{C}$ dating system. I also thank the staff members of the Nihon University Department of Geography, and those who contributed to establish the Radiocarbon Dating Laboratory of Nihon University, in operation since 1987. 


\section{REFERENCES}

Anderson, E. C., Arnold, J. R. and Libby, W. F. 1951 Measurement of low level radiocarbon. Review of Scientific Instruments 22: 225-230.

Arnold, J. R. 1954 Carbon-14 age method. In Faul, H., ed., Nuclear Geology: A Symposium on Nuclear Phenomena in Earth Sciences. New York, John Wiley \& Sons: 349-354.

Arnold, J. R. and Libby, W. F. 1949 Age determination by radiocarbon content. Checks with samples of known age. Science 110: 678-680.

Hertelendi, E., Csongor, E., Zaborszky, L., Molnar, J., Gal, J., Gyorffi, M. and Nagy, S. 1989 A counter system for high-precision ${ }^{14} \mathrm{C}$ dating. In Long, A., Kra, R. S. and Srdoz, D., eds., Proceedings of the 13th International ${ }^{14} \mathrm{C}$ Conference. Radiocarbon 31(3): 399-406.

Libby, W. F. 1955 Radiocarbon Dating, 2nd ed. Chicago, University of Chicago Press: $175 \mathrm{p}$.

Libby, W. F., Anderson, E. C. and Arnold, J. R. 1949 Age determination by radiocarbon contents: World-wide assay of natural radiocarbon. Science 109: 227-228.

Omoto, K. 1982 Development of BASIC program for radiocarbon dating. Science Reports of Tohoku University, 7th Series (Geography) 32(1): 14-45.

1985 Recent progress in radiocarbon dating techniques of Tohoku University. Science Reports of Tohoku University, 7th Series (Geography) 35(2): 95-105.
Otlet, R. L., Huxtable, G., Evans, G. V., Humphreys, D. G., Short, T. D. and Conchie, S. J. 1983 Development and operation of the Harwell small counter facility for the measurement of ${ }^{14} \mathrm{C}$ in very small samples. In Stuiver, M. and Kra, R. S., eds., Proceedings of the 11th International ${ }^{14} \mathrm{C}$ Conference. Radiocarbon 25 (2): 565-575.

Schoch, H., Bruns, M., Münnich, K. O. and Münnich, M. 1980 A multi-counter system for high precision carbon-14 measurements. In Stuiver, M. and R. S., eds., Proceedings of the 10th International ${ }^{14} \mathrm{C}$ Conference. Radiocarbon 22(2): 442-447.

Soini, E. and Kojola, H. 1977 An automatic gas counter for quantitative microdetermination of tritium in biologic material. Acta Pharmacologica et Toxicologica 41: 79.

van der Plicht, J., Streurman, H. J. and Schreuder, G. R. 1992 A new data acquisition system for the Groningen counter. In Long, A. and Kra, R. S., eds., Proceedings of the 14th International ${ }^{14} \mathrm{C}$ Conference. Radiocarbon 34(3): 500-505.

Walanus, A. $1986{ }^{14} \mathrm{C}$ electronic measurement system with a microcomputer. In Stuiver, M. and Kra, R. S., eds., Proceedings of the 12 th International ${ }^{14} \mathrm{C}$ Conference. Radiocarbon 28(2A): 569-570. 